\title{
Specialist Physician
}

National Cancer Institute

\section{Source}

National Cancer Institute. Specialist Physician. NCI Thesaurus. Code C73456.

A physician who receives additional education and training in one particular area of medicine 